\title{
CRISE ECONÔMICA, DESIGUALDADES, DIREITOS HUMANOS E ÉTICA DOS SISTEMAS DE SAÚDE NO CONTEXTO GLOBALIZADO'
}

\author{
Economic crisis, inequality, human rights and healthcare ethics in the \\ global context
}

\section{Ardigó Martino}

PhD em Políticas cooperação e políticas para o desenvolvimento sustentável International Centro Studi e Ricerche in Salute Internazionale e Interculturale E-mail: ardigo.martino@unibo.it

\section{Angelo Stefanini}

Pesquisador do Departamento de Medicina e Saúde Pública da Universidade de Bolonha e diretor científico do Centro Studi e Ricerche in Salute Internazionale e Interculturale, Dipartimento di Scienze Mediche e Chirurgiche. Università degli Studi di Bologna Alma Mater Studiorum E-mail: angelo.stefanini@unibo.it

\section{Resumo}

As escolhas relacionadas a alocação de recursos na Saúde Pública são constantemente pontos críticos, tanto em períodos de expansão econômica, quanto em períodos de crise. Em ambos os casos, as escolhas por racionamentos escondem numerosos perigos para a saúde da população, especialmente, quando são realizadas por meio de uma abordagem técnico-racional e sem reflexões éticas específicas. O racionamento feito a partir de decisões políticas raramente levam em consideração as reflexões estruturais do tipo ético sanitário, que deveriam ser utilizadas na organização, gestão e avaliação das políticas e serviços de Saúde. Este artigo visa fomentar o debate entre os profissionais de saúde, aos gestores e aos estudantes, demonstrando os riscos implicados na alocação dos recursos em saúde, por meio de um processo técnico-racional. Foram analisados referenciais teóricos e estudos de casos internacionais, relativos ao período pós Segunda Guerra Mundial até os dias atuais. A análise se constitui a partir da experiência e formação dos autores, bem como na capacitação dos profissionais de saúde tanto no contexto europeu, quanto no contexto brasileiro. O artigo reflete sobre a necessidade e a importância do "fazer ética", do ser sensível a diversidade moral em um mundo globalizado, procurando trazer potência na compreensão e mediação dos conflitos relacionados ao financiamento em saúde.

\footnotetext{
i Texto originialmente escrito em italiano publicado em 1999, Revista Sanità Pubblica, volume 3 sob o título Ética dei Sistemi Sanitari, em que os autores traduziram para o português, atualizaram e revisaram para esta publicação.
} 
Palavras chave: Ética; Alocação de recursos; Sistemas de saúde; Saúde global; Globalização.

\section{Riassunto}

Le scelte allocative rappresentano una criticità costante in salute pubblica sia in periodi di crescita economica sia in periodi di crisi. In tutti i casi le scelte di «razionamento» nascondono numerose insidie per la salute della popolazione, specialmente quando sono realizzate attraverso un approccio tecnico razionale e senza il supporto di specifiche riflessioni di natura etica. Infatti anche se il "razionamento» viene frequentemente presentato dai decisori politici e dai gestori come uno strumento per la promozione della salute quale diritto umano fondamentale, raramente riflessioni strutturate di tipo etico sanitario sono utilizzate nell'organizzazione, gestione e valutazione delle politiche sanitarie e dei servizi di salute. L'articolo tenta di fornire ai professionisti sanitari, ai gestori e agli studenti stimoli al ragionamento rispetto ai rischi insiti nell'allocazione delle risorse in salute eseguite solo attraverso processi tecnico-razionali. Sono stati quindi raccolti e riassunti i principali contributi teorici ed alcuni case studies internazionali relativi al periodo che va dal secondo dopoguerra ad oggi utilizzati dagli autori nella formazione rivolta ai professionisti sanitari sia nel contesto europeo sia nel contesto brasiliano. L'articolo dopo una riflessione estesa ed articolata conclude riaffermando la necessità e l'importanza del "fare etica" e dell'essere sensibili alle diversità morali, nel contesto pluralista del mondo globalizzato, sopratutto come strumento per la comprensione e la gestione dei conflitti che le scelte allocative in salute producono nel campo sociale.
Parole Chiave: Etica; Allocazione delle risorse; Sistemi sanitari; Salute globale; Globalizzazione.

\section{Abstract}

Allocation decisions are a critical constant in public health both in periods of economic growth and in times of crisis. In all cases "rationing" choices hide many dangers to the health of the population, especially when they are made through a rational, technical approach and without the support of unambiguous ethical considerations. In fact, even if "rationing" is frequently presented by policy makers and managers as a tool for the promotion of health as a fundamental human right, well-thoughtout, ethical reflections on health are rarely used in the organization, management and evaluation of health policies and health services. The article aims at encouraging health professionals, managers and students to reflect on the risks inherent in resource allocation in health driven only by technicalrational processes. A number of significant, theoretical contributions are presented, together with international case studies from World War II to the present, utilised by the authors to train health professionals both in Europe and in the Brazilian context. After an extensive and articulated discussion, the article concludes reaffirming the need and importance of "doing ethics" and being sensitive to moral diversity, in the pluralist context of the globalized world, as a tool for understanding and managing conflicts generated in society by healthrelated allocation decisions.

Keywords: Ethics Resource allocation; Health systems; Global health; Globalization. 


\section{Introdução}

A maturação do processo de globalização, onde a economia liberal está produzindo em larga escala o aumento das desigualdades sociais seja entre os países ou dentro destes ${ }^{1}$, intensificado pela crise econômica europeia, ${ }^{2}$ o declínio das nações de modelo do século $X X$ e o surgimento de novas formas de agregação de poder econômico do tipo trans-nacionais ${ }^{3,4}$ contribuiu para a erosão do conceito de bemestar, redimensionando os mecanismos de redistribuição dentro das nações, agravando ainda mais as desigualdades. Todos esses fatores colaboraram para uma transformação radical do quadro simbólico, político, econômico e cultural em relação aos direitos humanos.

Neste cenário, o agravamento da crise econômica internacional potencializa o risco da substituição progressiva da ética pela lógica técnico-racional do capital dentro dos serviços de saúde. Os sistemas sanitários de moldes igualitários são forçados a realizar uma progressiva reestruturação em nome da eficiência e da redução dos gastos ${ }^{5,6,7}$. Economias, racionalização de gastos, eficácia e eficiência, são conceitos muito traiçoeiros, exigidos pelo mercado e pelo liberalismo, já que estes geram facilidades em se ocultar os processos de exclusão, discriminação social e produção de desigualdades ${ }^{8}$. Entre eles, a Itália, pela sua história de um sistema de saúde equitativo com molde Beveridgiano e o Brasil por seu modelo integrado e participativo de cuidados primários em saúde.

Desta forma, realizar escolhas de financiamento no âmbito do setor de saúde não significa simplesmente reduzir ou aumentar inequidades, mas sim decidir quem obterá qual serviço e qual serviço será mais ou menos priorizado. Este discurso vale para países em expansão econômica, como o Brasil, ou em crise econômica, como a Itália, nos quais em cada caso é desafiador estabelecer quais necessidades devem ser prioritariamente inclusas ou exclusas dentro do painel dos serviços públicos. Seja no corte de gastos ou na expansão dos serviços, a decisão sobre a distribuição dos recursos se configura inevitavelmente em um exercício de racionamento ${ }^{9}$.

É consolidada a ideia que existe uma divisão entre a lógica de gestão do sistema sanitário baseado no mercado e a lógica de gestão baseada no estado de bem estar social, e que basta escolher um sistema em detrimento do outro para obter os resultados coerentes com a premissa em virtude dos quadros teóricos de referência.

Em um sistema de saúde privado, com base no mercado, o acesso aos serviços e "quem obtém o que" é determinado pela vontade e pela capacidade de pagar que cada indivíduo tem. Os prestadores dos serviços respondem então à demanda dos consumidores, mas impulsionados por uma vontade de lucro. Em uma situação de concorrências, o equilíbrio é mantido mais ou menos por ajustes automáticos dos preços.

Em um sistema de saúde público, o acesso é teoricamente determinado pelas necessidades, as quais os prestadores de serviços respondem guiados por um motivo sócio-humanitário. 0 equilíbrio, neste caso, é mantido por um programa baseado nas necessidades da população. Essas necessidades podem naturalmente assumir significados muito diferentes, segundo quem as define. Por exemplo, existem necessidades perceptíveis à comunidade que não correspondem àquelas identificadas pelos profissionais de Saúde. As demandas podem ser diversas em base da sua prevalência, em relação à severidade, de acordo com as pessoas afetadas (em termos de número e de importância social) e em relação ao nível de interesses políticos que elas geram.

Em um sistema de saúde privado, nenhuma pessoa em particular, a não ser o 
próprio mercado, decide como os recursos devem ser aplicados. Já em um sistema público, baseado em uma programação, alguém deve ter a vontade - optar pela escolha, ou pela escolha de não escolher -, deve possuir o poder de legitimar o controle sobre políticas sociais, econômicas e sua capacidade de decisão - isto é, possuir informações, saberes, valores e mecanismos adequados.

Isto cria um contexto em que a política é construída e declarada, em continuidade com um mundo de valores, que na prática apresenta uma série de implicações produtivas, mas não só produtos de valor. Como no caso italiano, a importância da lógica da gestão dos sistemas de saúde, no âmbito do sistema de welfare (Estado de Bem Estar), motivou-se pela contenção dos resíduos da ineficiência. Com a reforma sanitária de $1992,{ }^{10}$ impôs um orçamento baseado nos serviços de saúde em nome do Direito a Saúde mas sem adotar instrumentos de competência de avaliação e gestão do impacto sobre a produção da assistência dentro do serviço, senão aqueles próprios da administração em saúde que são operacionalizados e discutidos entre o nível político e a gestão.

Ao invés disso, na vida cotidiana, as decisões sobre como gerir os recursos de um sistema de saúde, ocorrem em todos os níveis ${ }^{11}$. Começando pelo ambulatório, onde o paciente aguarda para ser atendido em uma sala de espera lotada e desconfortável, em que sua consulta pode ser adiada por alguns dias (racionamento por dissuasão ou por retardo). Continuando quando o paciente chega encaminhado de outra clínica ou laboratório por razões de competência (racionamento por deflexão), quando o médico examina o paciente e decide qual o caminho a seguir, isto é quantos exames e quantos medicamentos prescrever, se envia o paciente a um especialista ou deve hospitalizá-lo (racionamento por diluição). Finalmente, hospitalizado, alguém deve decidir quando liberá-lo do hospital ou por quanto tempo mantê-lo ali (racionamento por interrupção). Essas são as microdecisões, em nível de primeira linha de cuidado em saúde, em exemplo, a medicina de base especialista ou hospitalar.

No nível superior da pirâmide, as macro-decisões são tomadas pelo governo (por exemplo, a quantidade de recursos destinados à Saúde, em relação a outros setores), dentro de um órgão executivo, como um Ministério da Saúde (por exemplo, a prioridade dada à prevenção, ao cuidado e à reabilitação) $)^{12}$. Este processo de escolhas de prioridades ocorre por meio de um processo de racionalização da quantidade e dos tipos de serviços prestados aos diversos grupos da população, representados pela demanda diária, mesmo que tudo não seja assim tão explícito e consciente. Cada decisão desse gênero tem ainda sua racionalidade, no sentido que a ação (isto é, o meio) escolhida deve ser coerente com a norma (isto é, com a finalidade) pela qual é dirigida. E que para um mesmo problema podem ser aplicadas diferentes formas de racionalidades.

No debate em saúde é possível emergir a dimensão ética inevitável das escolhas racionais. Um profissional da saúde, por exemplo, é perfeitamente racional se decide que, já que as doenças infecciosas são combatidas e erradicadas, a presença da tuberculose em uma comunidade deve ser, o quanto possível, reduzida tecnicamente à zero. Um economista pode, em vez disso, chegar à conclusão que uma vez que o empenho para controlar a doença condiz com um aumento significativo no custo unitário do programa, é aconselhável chegar a uma redução mais modesta, ou até mesmo não intervir e usar os recursos disponíveis para melhorar a condição econômica da população. Um político, por outro lado, pode decidir não interferir diretamente sobre a tuberculose, porque a tuberculose não ocupa uma grande 
importância ao nível da opinião pública. Portanto, uma intervenção para combater este problema traria apenas modestas vantagens para o próprio partido. Se aceita a validade das respectivas normas, qualquer uma dessas escolhas é perfeitamente racional, na medida em que os meios escolhidos condizem com os critérios que as sustentam. Isto significa que a racionalidade para uma pessoa pode corresponder a irracionalidade, desonestidade, ou falta de realismo para outra pessoa. Uma prioridade pode ser correta ou errada em relação à norma e ao processo utilizado, mas não em sentido universal e abstrato.

É possível pensar, por exemplo, no conceito de aparência paradoxal, de racionalidade emocional, segundo o qual, certas decisões, ligadas não só à esfera pessoal, mas também ao comportamento e ao sentimento coletivo dentro de uma organização, parecem possuir tal componente de norma emotiva que, se fosse baseada somente em cálculos exclusivamente intelectuais, poderiam adquirir resultados irracionais. Enfim, é possível individualizar uma lógica de organização que poderia ser denominada racionalidade superior ou de gestão que representa uma síntese de modos diferentes de se tomar decisões e fazer escolhas.

Tal síntese acomoda diferenças óbvias e conflitos que existem entre as várias racionalidades, produzindo explícitos critérios de relevância e deixando à disposição informações justas e pertinentes para qualquer problema, de modo que sejam utilizados os métodos mais apropriados para tomada de decisões ${ }^{13}$. Infelizmente, na realidade, a seleção dos critérios de escolha de prioridades, ao invés de ser parte de um processo analítico de decisão e realizado "à luz do dia" (no qual existe uma ampla oportunidade para que todos participem, que em razões diversas possam confrontar a evidência dos fatos e em que os conflitos de valores e preferências possam ser plenamente explorados) são extremamente deixados ao acaso, às tendências do momento.

Duas coisas devem ser enfatizadas no processo de racionamento descrito até agora: em primeiro lugar, as microdecisões sobre prioridades ao nível de base são, geralmente, condicionadas pelas macro-decisões relacionadas à aplicação de recursos nos níveis superiores da hierarquia organizadora.

$\mathrm{Em}$ segundo lugar, em qualquer nível de tomada de decisão, as escolhas devem ser realizadas de acordo com as necessidades. Entretanto, tudo depende de como essas necessidades são identificadas, isto é, pelas diversas racionalidades que prevalecem particularmente naquele momento. Quando se fala de escolha de prioridades, em efeito, discute-se uma complexa interação de múltiplas decisões sobre como aplicar os recursos, guiando-se por diferentes critérios e por vários níveis organizacionais.

Como as diversas racionalidades são moldadas inevitavelmente pelos valores e critérios, é comum se perguntar quais destes devem ser utilizados. Por exemplo, a prioridade a ser dada nos planos de saúde tanto em âmbito nacional como local, por quem distribui as reservas, deve respeitar a individualidade dos grupos da população. Esta definição pode ser feita com base em áreas geográficas; com base nos grupos populacionais (grupos ocupacionais, sociais, de diversas classes, variedade dos grupos em riscos, etc); com base nos grupos de pacientes e/ou tipos de interdependência (HIVsoropositivos, idosos, toxicodependentes, mães e filhos, etc); com base em atividades e serviços diferentes (decidir a prioridade entre os serviços primários, secundários ou terciários, com particular resguardo à quantidade, qualidade, eficácia e eficiência); com base nas diversas formas de intervenção (prevenção ou cura); com base nas diversas agências e organizações (seja 
no setor público ou privado).

Tais dimensões são obviamente interdependentes: dar prioridades a serviços de nível secundário (hospitais) tenderá a beneficiar particularmente a alguns grupos sociais (classe urbana) e algumas doenças particulares (aquelas que necessitam de hospitalização). O pacote de cuidados essenciais foi à estratégia proposta nos anos noventa pelo Banco Mundial aos países em desenvolvimento e é proposta agora também para a Europa devido à crise econômica ${ }^{14}$. Esse pacote consistia na limitação do número e dos tipos de intervenções, privilegiando aqueles com maior relação custo/benefício, os quais os governos desses países deveriam financiar, devido ao corte de gastos no setor de Saúde.

Isto representa um típico exemplo do racionamento assistencial em saúde por exclusão, e foi promovido como a resposta mais racional e científica ao limitados recursos disponíveis. Porém, na realidade, seria possível utilizar muitas outras estratégias.

Por sorte, apesar dos economistas, seja em período de crise econômica, seja durante a expansão, a comunidade (ou pelo menos uma parte dela) pede satisfação aos profissionais da área da saúde sobre quais são as considerações não apenas de ordem econômica, mas também político, filosófico e ético que guiam as escolhas organizativas.

Uma das dificuldades na utilização da ética por parte dos profissionais da área da saúde é a expectativa de que esta forneça respostas objetivas a partir de um processo de decisão racional, através de um algoritmo imutável. Ao contrário, as reflexões éticas são desnaturalizantes, ou seja, elas necessitam de uma escolha entre teorias ou princípios morais, tendo-os em contraste. O raciocínio sobre ética pode iluminar o problema, mas não pode fornecer uma modalidade incontestável de escolha entre modelos morais, portanto, necessita de um posicionamento definitivo dos profissionais, abandonando a sua presumida posição de observadores neutrais da realidade. Liberando o debate em relação a alocação de recursos na sua dimensão da imparcialidade, porém, se permite a reimersão em seus conteúdos sociais, culturais, políticos e com eles a participação comunitária e a riqueza da subjetividade que animam a sociedade ${ }^{15}$.

A desnaturalização e a subjetivação não significam 0 abandono do rigor científico em favor do relativismo indiscriminado, mas ao contrário, desviam as atenções das "normas éticas" à ética dos processos. Forçar os profissionais à autoreflexão e à avaliação contínua das produções sociais das próprias práticas. Por exemplo, a partir do quadro conceitual da liberdade individual em relação à liberdade coletiva, nós podemos enunciar 4 princípios ou indicações processuais (definidas prima facie, ou seja, vinculadas a menos que, em determinadas circunstâncias, elas não entrem em conflito com obrigações de força igual ou maior. Nesse caso deverá ser feita uma escolha entre eles.) que direcionam as escolhas dos profissionais da área da saúde sem representar prescrições normativas. Estes princípios são:

\section{Respeito pela autonomia}

Representa a tentativa de tornar-se efetiva a autodeterminação do sujeito, a partir do pressuposto que os indivíduos devam ser colocados em condições de alcançar o seu bem estar mas que este não pode ser alcançado sem a sua participação. É o princípio mais consistente entre os quatro e equivale ao imperativo categórico de Kant "trate os outros como fins em si mesmos e nunca como meios". Em termos de saúde indica, por exemplo, a necessidade de compartilhar com o paciente as informações oportunas não para induzi-lo a alcançar os resultados que imaginamos serem os melhores para ele, mas para que ele possa refletir sobre que coisas são melhores para si próprio; 
2. Não-maleficência

É um princípio que se antepõe ao benefício, porque reflete sobre a normalidade do benefício sem o outro. A nossa tensão como profissionais da saúde é aquela de agir sem limitar as liberdades do indivíduo (não prejudicá-lo exatamente), além de não efetuar ações que possam prejudicá-lo diretamente, pesquisar a sua emancipação para que possa participar plenamente das ações benéficas que o tornem ativamente consciente;

\section{Beneficência}

A pesquisa do bem do paciente pode, portanto, ocorrer de maneira participativa, envolvendo o paciente a partir das suas trajetórias de vida e da sua subjetividade;

\section{Justiça}

lustitia est ad alterum, neminem laedere, suum cuique tribuere." É talvez o princípio mais problemático entre todos, porque a questão da justiça é aquela que mais coloca em questionamento os horizontes simbólicos e os sistemas morais de quem os observa. Em relação à alteridade nós podemos assim resumir duas grandes macros áreas da justiça:

a) Comutativa (linear, horizontal/ direta, bilateral, indivíduo-indivíduo, aritmética, igualitária, reparadora).

b) Distributiva (triangular/tripolar, vertical/direta, horizontal/indireta, distribuição segundo proporcionalidade).

A reflexão sobre justiça, alteridade e equidade torna-se então outro elemento central na construção da ética no momento que cada um de nós é a favor da justiça mas nem todos faremos a mesma interpretação. A esquerda do "espectro político" tende a dar prioridade à "justiça social" com a intenção de reformar a sociedade na direção a uma maior igualdade, eliminando a pobreza. A direita por sua vez prefere concentrar-

\footnotetext{
ii Justiça é para outra pessoa, para não ferir ninguém, para dar a cada um seu direito.
}

se sobre a força da lei e da ordem, da estabilidade e da adequada recompensa à iniciativa privada e ao mérito individual. Uma primeira importante formulação do princípio de justiça virtualmente aceita por todos é aquela de Aristóteles segundo o qual "os iguais devem ser tratados de modo igual, enquanto os diferentes devem ser tratados de modo diferente, proporcionalmente às suas relevantes desigualdades". A aceitação deste princípio de qualquer modo nos assegura pelo fato que as decisões terão uma justificativa ética e não estarão sujeitas a algum arbítrio ou parcialidade. O problema que se encontra na definição aristotélica, entretanto, é que é exclusivamente formal, não nos diz nada do conteúdo e da substância com o qual, por exemplo, se pode definir e medir a igualdade ou a desigualdade de dois ou mais indivíduos. Portanto, necessitamos de uma série de princípios que funcionem com critérios para uma justa distribuição dos recursos. São os chamados princípios "materiais de justiça". Qualquer formulação de uma política ou de um endereço público deriva da aceitação (ou da recusa) de um ou mais dos tais princípios materiais de justiça distributiva.

São eles ${ }^{16}$ :

A cada um, segundo uma subdivisão em partes iguais;

A cada um, segundo a necessidade;

A cada um, segundo a própria contribuição;

A cada um, segundo o empenho e o esforço realizado;

A cada um, segundo o mérito;

A cada um, segundo as leis do mercado.

Ao formular as próprias políticas sociais a maior parte da sociedade recorre, de modo geral, contemporaneamente, a mais de um destes princípios. Por exemplo, pelo menos em teoria os subsídios são atribuídos aos pobres e aos desempregados (necessidade), os postos de trabalho com 
base em títulos e concursos (mérito), os níveis dos salários com base nas forças do mercado, enquanto a instrução pública primária é aberta igualmente a todos os cidadãos (partes iguais). É também óbvio que cada um dos princípios acima elencados ocupe uma posição mais ou menos privilegiada segundo a tendência política dominante naquela sociedade. Não obstante as diversas teorias concordam sobre o dito latino "unicuique suum" (a cada um o seu), onde falta o acordo é na definição de que coisa concretamente seja esse "seu". Aquilo que fazem, entretanto, é estabelecer as bases sobre as quais se deve distribuir benefícios e encargos. A um extremo está então a máxima "a cada um segundo a própria necessidade, a cada um segundo as próprias possibilidades" (teoria igualitária/socialista) enquanto em outro encontramos "a cada um segundo quanto honestamente adquirido em uma livre economia de mercado" (teoria libertária/ liberal).

\section{Teorias da justiça}

As teorias mais importantes que tratam de coisas que se pode dizer certa ou errada são aquelas deontológica e aquela teleológica (ou consequencialista). A primeira se baseia em princípios que estabelecem coisas que sejam justas ou injustas independentemente das suas consequências. Tais princípios são frequentemente evidentes por si mesmos e tratam dos deveres (ser justo com os outros, beneficência, não maleficência, etc) e dos direitos (de autonomia, de liberdade e de igualdade). Uma ação particular é então correta quando se conforma a tais princípios. O problema desta proposta é que ela não dá indicação de como comportar-se quando dois ou mais destes princípios entram em conflito entre si (por exemplo, autonomia e beneficência). A proposta teleológica afirma responder a esta dificuldade propondo que a bondade de uma ação deva ser julgada pelos efeitos, resultados e consequências que produz. São fundamentalmente três as teorias da justiça que influenciaram, em tempos e modos diferentes, a política de saúde do governo e organizações internacionais: a libertária, a igualitária e a utilitária. As duas primeiras são do tipo deontológico, a terceira teoria é do tipo teleológico.

\section{Teoria libertária}

Segundo a teoria libertária para justiça se deve, sobretudo, entender a defesa da autonomia e da liberdade (prevalentemente econômica) do indivíduo. O conceito de justiça distributiva, que permite retirar quaisquer bens adquiridos honestamente para dá-los a outros necessitados (por exemplo, através de uma tributação progressiva) é de fato estranho a este pensamento que vê no mercado de livre concorrência o único mecanismo permitido (e certo) para redistribuir as riquezas. As desigualdades que deste modo podem ser criadas não são injustas porque o mercado termina por recompensar "quem se dá a fazer e trabalha duro". Também no setor de saúde é preconizada a intervenção do mercado e a expansão do privado para consentir a livre concorrência entre os fornecedores e eventualmente também entre os financiadores dos serviços de saúde. Intrínseco a esta teoria está o conceito de mérito, segundo o qual uma pessoa ou um grupo "mereça" ou não prioridade na alocação dos recursos sanitários com base no próprio estilo de vida. Tal interpretação da justiça distributiva coloca evidentemente uma ênfase toda particular sobre a escolha individual considerada livre e que se faz a cargo das próprias responsabilidades. As causas sociais que poderiam estar na base da doença e colocar em discussão a efetiva liberdade de escolha do indivíduo não são considerados neste caso. 


\section{Teoria Igualitária}

$\mathrm{Na}$ teoria igualitária justiça significa equidade. Mas no setor de saúde existem pelo menos quatro diferentes definições de equidade ${ }^{17}$. A primeira (igualdade de despesas em saúde per capita) está na base de certos métodos de alocação regional dos recursos segundo determinadas fórmulas (população, mortalidade, etc) usados em alguns países. (Se percebe que a diferença entre "igualdade" e "equidade", onde a primeira resguarda a distribuição dos recursos de modo igual para todos independentemente das necessidades individuais e que então pode produzir êxitos diversos em termos de saúde). A segunda definição (distribuição segundo a necessidade), de aparência simples e clara, é porém complicada pela dificuldade de definir o conceito de "necessidade". Tal princípio se apresenta, invocando à definição aristotélica de justiça, em duas versões: uma, a chamamos "horizontal" (pessoas com as mesmas necessidades deveriam ser tratadas do mesmo modo) e uma "vertical" (pessoas com necessidades maiores deveriam receber maiores considerações que aquelas com necessidades menores). A mesma necessidade pode ser vista como "nível inicial de saúde" ou doença, no sentido que pessoas que são mais doentes que as outras têm mais necessidade. Mas necessidade de que? De assistência sanitária? O que dizer se não existe uma cura eficaz para a minha doença? Talvez então terei necessidade de outros benefícios alternativos. Além disso, a eficácia de uma intervenção é uma condição necessária, mas não suficiente para satisfazer uma necessidade: poderiam realmente existir outras tecnologias mais econômicas ou mais produtivas que alcancem o propósito de modo mais eficiente (isto é, satisfazendo a mesma quantidade de necessidade mas com um menor uso de recursos). Em conclusão, um indivíduo pode então ter necessidade de assistência em saúde apesar de não estar doente (necessidade de medidas preventivas), ou estar doente, mas não ter necessidade de assistência em saúde (onde nenhuma intervenção pode ser eficaz), ou ser doente e ter necessidade de uma cura tipo $X$ (com uma boa relação custo-eficácia) mas não da cura do tipo $Y$ (que é extremamente dispendiosa). A terceira definição considera a equidade como igualdade de acesso. A necessidade no campo da saúde vem sempre identificada também como acesso (expressão da oferta aos serviços) ou como utilização (expressão das demandas). O uso comum que se faz dos termos parece adaptar-se melhor à definição de acesso como "o consumo máximo alcançável" do produto ou serviço em questão. Podem realmente existir diversos graus de acesso a tais serviços e assim também um limite máximo ao seu consumo. Acesso (ou melhor, a falta de acesso) pode também ser entendido como "uma utilidade falha" medindo os custos em termos de utilidade ao invés que em dinheiro. Assim uma vez que a utilidade marginal da renda (o benefício/utilidade adicional baseado em uma unidade de renda superior) é maior para o pobre que para o rico, também o "custo de acesso" será mais alto (e então o acesso menor) para o pobre também se este deve pagar o mesmo preço em dinheiro. Para usar certa quantidade de assistência a pessoa mais pobre deve sacrificar mais, isto é, deve se privar de algo que para ele tem um valor maior do que para quem é rico. A outra metade consiste na qualidade (output) e no êxito final (outcome) do serviço oferecido.

\section{Teoria Igualitarista}

A última definição descreve a equidade no setor sanitário como igualdade no nível de saúde. O igualitário é movido por espírito altruístico, quase religioso, para superar a dimensão fortuita e acidental 
da distribuição das riquezas e eliminar as desigualdades naturais (herdadas no nascimento) e sociais (sofridas durante a vida). Reconhecendo os limites dos recursos à disposição frente a uma demanda em saúde praticamente ilimitada, o pensamento igualitário propõe que tais recursos escassos não sejam deixados à mercê do mercado mas que sejam empregados onde há uma maior necessidade e que isso esteja bem definido. O problema desta concepção é que justamente onde existe uma maior necessidade (pensemos no doente terminal) que frequentemente é menos eficiente intervir enquanto se corre o risco de utilizar quantidades enormes de recursos em um poço sem fundo (bottomless pit) à custa de outras intervenções com maiores probabilidades de sucesso.

\section{Teoria Utilitarista ou utilitarismo social}

A teoria utilitarista, ao contrário das duas precedentes, coloca uma preocupação do tipo gerencial e eficiente sobre os efeitose sobre as consequências das ações humanas. Como visto acima, os utilitaristas acreditam que justiça seja não tanto prender-se a certos princípios (visão deontológica) que muito frequentemente entram em conflito entre si, mas ao contrário, produzir resultados desejáveis (visão teleológica) e minimizar aqueles indesejáveis. $O$ ideal é alcançar o bem máximo e a felicidade para a maior parte da população (ou seja, obter aquela que é chamada utilidade máxima). No setor de saúde, entre recursos finitos e demandas sem limites, é então necessário alcançar compromissos que maximizem os benefícios e minimizem os custos em favor do maior número de pessoas (que não são necessariamente as mais necessitadas). Disponibilidade econômica do Estado e pressões políticas devem então ser os fatores determinantes para decidir se promove ou não um nível mínimo de serviços de saúde para todos: "os argumentos para justificar o direito à saúde e à assistência sanitária devem verter sobre a legitimidade das despesas sociais ao invés de uma noção de direitos naturais, inalienáveis e pré-

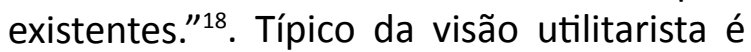
o uso das análises econométricas (custo/ benefício, custo/eficácia e custo/utilidade) e de índices como os QALYs (Quality Adjusted Life Years) ${ }^{19}$ e DALYs (Disability Adjusted Life Years $)^{20}$ que representam uma medida aparentemente objetiva do ganho em saúde (health gain) obtido através de intervenções clínicas diferentes.

Os QALYSs em particular, são produzidos através da correlação entre o impacto sobre a mortalidade e morbidade (definida com base na mobilidade e na dor) dos tratamentos específicos e a qualidade de vida, esta última definida por meio de pesquisa de opinião em amostras de usuários. Diversos tratamentos serão, evidentemente, associados com diferentes valores destas variáveis e pode, assim, serem catalogados de acordo com maior ou menor número de produtos QALYs. O problema principal desta teoria, então, é que a maximização da utilidade não significa necessariamente justiça. Pelo contrário, em certos casos o raciocínio utilitarista apresenta conclusões bastante desconcertantes como quando o bem da maioria conduz a legitimação da injustiça em detrimento das minorias. É evidente que a "a utilidade medida segundo o método custo/ benefício não pode trazer a negação do princípio da equidade ao ponto de alguém permanecer sem algum tipo de assistência sanitária". ${ }^{21}$ É necessário, do ponto de vista ético (ainda que nem sempre a partir do econômico), que o princípio da igualdade de acesso de todos os cidadãos a um nível mínimo aceitável aos serviços de saúde, acompanhe sempre cada consideração de utilidade. Então as consequências não anulam os princípios, mas sim os ordenam por importância. ${ }^{22,23}$ 


\section{A proposta contratualista}

Uma proposta interessante ${ }^{24}$, a qual afirma que uma sociedade justa deveria ser orientada por dois princípios: liberdade e igualdade. Questiona quais definições de justiça seria dada por uma pessoa racional que fosse colocada atrás do que ele chama de um "véu de ignorância", ou seja, sem conhecer a sua posição dentro da sociedade em que vive. Partindo desta situação imaginária, como conceber uma sociedade justa? Muito provavelmente ele optaria por uma sociedade a qual ele não devesse sacrificar sua liberdade, mas ignorando a condição de ser pobre ou rico, as desigualdades fossem minimizadas, sendo permitida somente se fossem beneficiados os menos favorecidos. Em tal sociedade, o sistema de saúde deveria retirar todos os obstáculos, seja financeiro ou social, racial ou geográfico, para o acesso a um determinado nível de serviços de saúde. Sem um mínimo de serviços de saúde para todos, de fato, qualquer ideia de liberdade e igualdade de oportunidades para todos não se sustentará. Isto só é permitido apenas por um planejamento adequado que regula e orienta o mercado. Como visto anteriormente, o conceito de equidade deriva naturalmente daquele da justiça, em particular da justiça distributiva. Assim, esclarece sua posição: "Todos os bens sociais primários (liberdade e oportunidade, renda e riqueza, e as bases de auto-respeito) devem ser distribuídos igualmente, a menos que uma distribuição desigual, de qualquer ou de todos estes bens, seja para o benefício dos menos favorecidos." ${ }^{24: 303} \mathrm{O}$ que, aplicado ao setor da saúde, poderia ler-se: qualquer serviço de saúde prestado deveria ser disponibilizado para todos igualmente, a menos que uma distribuição desigual seja realizada em benefício dos menos favorecidos. A experiência dos países que estão reformando seu sistema de saúde vai nesta direção. O exemplo de Oregon ${ }^{25}$ foi, em alguns aspectos, sui generis, em que o objetivo do experimento de "priorização" de combinações de condição/tratamento era estender a cobertura dos serviços a um número maior de pessoas não seguradas e, logo, totalmente fora do sistema. O resultado foi a introdução de um tipo de racionamento (a redução do número de serviços de suporte, a fim de alcançar, com aquela escolha, um maior número de pacientes) no lugar do até então existente (com a exclusão de um setor da população, os não segurados, do financiamento). Neste processo de racionamento de serviços para exclusão do pressuposto de partida, segundo o qual a lista de intervenções prioritárias foi determinada por instrumentos técnicos (analise custo-eficácia), mostrou-se claramente inadequado, levando às vezes a resultados paradoxais (como dar prioridade a revestimentos odontológicos em relação à apendicectomia), sendo imediatamente abandonado. Neste sentido, a experiência de Oregon foi útil para países como a Holanda ${ }^{26}$, Suécia ${ }^{27}$ e Nova Zelândia ${ }^{28}$ para decidir o que não fazer: não produzir um conjunto limitado de intervenções com a exclusão de outros. Mesmo no caso de tratamentos comumente considerados de baixa prioridade poderia de fato surgirem circunstâncias individuais (como a cirurgia plástica para uma bailarina) que oferecem argumentos suficientemente fortes a favor da sua importância e da necessidade do seu financiamento.

\section{Ética e alocação de recursos}

A abordagem ética representa a base inevitável de partida, o último elemento que condicionará a escolha e que deverá caracterizar todo o quadro conceitual de referência.Seja qual for a decisão, esta deverá ser eticamente defensável. O critério que eventualmente resultará mais satisfatório dependerá, de modo determinante, dos 
valores e da ideologia inspiradora de quem toma a decisão. Parece bastante evidente como a tendência igualitária e o apelo ao conceito de necessidade são típicos de uma visão solidária (social-democrata) da vida política enquanto o individualismo, o conceito de mérito e de mercado como último regulador da vida social e econômica são parte de uma visão neoliberal da sociedade. Esta última posição considera a prestação de serviços de saúde para os pobres como uma questão de caridade e não de justiça, mesmo em uma sociedade que apresenta esta concepção, deveria garantir mínimos e decentes cuidados de saúde para todos ${ }^{29}$. Uma proposta alternativa, como vimos, é aquela ${ }^{24}$ que, partindo do pressuposto que a assistência em saúde e, sobretudo, a estado de saúde estão condicionadas às oportunidades de disposição de cada um, sugere uma distribuição de recursos (incluindo cuidados de saúde) exatamente a permitir que todos tenham acesso à igualdade de oportunidades. Qualquer que seja a posição tomada e os critérios adotados para a escolha, haverá sempre a necessidade de se referir ao aspecto econômico, os limitados recursos disponíveis, para os custos que as escolhas feitas envolverem. A decisão de financiar uma determinada intervenção implica ao mesmo tempo a escolha de não financiar outro, logo, subtrair-se de alguém um provável benefício. Daí, a enorme dificuldade encontrada na pesquisa de uma teoria da justiça aplicada ao setor da saúde, dificuldade que se expressa na necessidade de articular a escolha sobre dois momentos essenciais: o momento deontológico, feito de princípios e de imperativos categóricos (satisfazera necessidade ou premiaromérito) que não consideram as consequências como moralmente relevantes e o momento teleológico que está nas consequências das ações que tem seu significado moral a justiça então consistiria principalmente na maximização dos resultados positivos ${ }^{30}$.
Nasce, assim, o dualismo equidade (momento deontológico) - eficiência (momento teleológico), cuja resolução representa provavelmente o maior desafio que uma comunidade moral enfrenta no processo de alocação de recursos limitados.

\section{Prós e contras da abordagem utilitária}

A teoria utilitarista, que se refere aos princípios formulados pelo filósofo Jeremy Bentham ${ }^{31}$ (1748-1832), segundo a qual "a maior felicidade para o maior número é a medida de certo e do errado", apela ao momento teleológico da dicotomia descrita acima. As prioridades, argumenta, deveriam ser determinadas de modo a conduzir ao melhor resultado possível. Tal êxito consiste no maior número de resultados desejáveis e nomenornúmeroderesultadosindesejáveis: esta é a chamada máxima utilidade. Para obter este resultado ocorre maximizar os benefícios e minimizar os custos a fim de alcançar a maior parte da população (a mais numerosa, não necessariamente a mais necessitada). Esta abordagem tende a se concentrar em técnicas econométricas tais como: a análise de custo-eficácia e a análise custo-utilidade. No primeiro caso, uma vez calculado o custo unitário de um resultado favorável (por exemplo, a cura de uma veia varicosa que não necessita de outras intervenções por pelo menos três anos) obtida através de intervenções alternativas (cintas, injeções esclerosantes, etc.), podemos, ao nível micro, escolher a intervenção (ou o paciente) menos dispendioso. No nível macro, no entanto, a escolha é entre tratamentos diversos de diferentes doenças e, portanto, é muito mais difícil definir qual seja a eficácia final sobre o paciente. Daí o conceito de utilidade em potenciais pacientes como medida em termos de resultados finais e avaliada com base na medida da qualidade 
de vida; o número de anos de vida ganhos ou fórmulas que juntas combinam vários critérios, tais como SIP (Sickness Impact Profile), o NHP (Nottingham Perfil de Saúde), - QALY (Quality Adjusted Life Years) ou DALYs (Disability Adjusted Life Years). Estas medidas levantam diversas questões éticas que estão relacionadas com o valor da vida de um indivíduo, um valor que só pode ser estimado pelo próprio sujeito em questão e não, por exemplo, pela sua contribuição para a produção global da sociedade em que ele vive.

Além disso, com esta abordagem, os pacientes jovens terão prioridade sobre os aqueles idosos, as doenças agudas sobre aquelas crônicas e debilitantes, e assim por diante. Minorias com doenças de alto custo para se chegar à cura e com moderada probabilidade de expectativa de vida serão, assim, inexoravelmente excluídos em favor dos demais. É fácil vislumbrar como emergente o princípio do mérito no argumento de alguns para a sustentação de que um ano de vida saudável de uma mãe de três filhos vale mais, por exemplo, que um ano a vida de uma mulher solteira. As vidas de indivíduos diferentes são de valor imensurável, valor que não pode ser reduzido pela multiplicação de cada um deles por um fator QALY. Quem pode dizer se a senhora idosa $X$ considera os poucos anos que lhe restam para viver mais ou menos do que o jovem $Y$ avalia a sua (provavelmente muito mais longa) existência? Além disso, a maximização da utilidade total não nos diz absolutamente nada sobre a sua efetiva distribuição dentro da sociedade ${ }^{32}$. 0 julgamento utilitarista sobre as ações, como vimos, baseia-se unicamente nos resultados e não em seu conteúdo moral intrínseco. De acordo com tal atitude, o bem da maioria pode levar à legitimação de injustiça para com as minorias que possuem como única culpa, serem portadores de condições muito custosas. O que resulta evidente é que a equidade e a eficiência podem estar em conflito entre si, enquanto a maximização dos benefícios não conduz necessariamente à sua distribuição equitativa.

\section{Conclusão}

Nos últimos anos desenvolveu-se um debate internacional muito vivo sobre vários tipos de racionamento de recursos da saúde. Vários países enfrentaram explicitamente o problema, cada um em sua própria especificidade, propondo estratégias e possíveis soluções. Em geral, se pode dizer que são dois fundamentalmente os caminhos percorridos que refletem na prática a dicotomia tradicional entre utilitarismo, em seu aspecto radical (Oregon) ou mais atenuado (Holanda), e igualitarismo, seja esse eticamente fundado (Suécia) do que alcançado com a ajuda da ciência sob a forma de "medicina de evidência" (Reino Unido e Nova Zelândia). Obviamente, as escolhas feitas pelos diferentes países não podem deixar de refletir as diferenças, específicos contextos culturais, políticos, econômicos e sociais dentre os quais foram realizadas e em particular o tipo de sistema de saúde existente. Se, de fato, a decisão do Estado de Oregon (e, em alguns aspectos, semelhante, Holanda) para um tipo de racionamento por exclusão, onde somente uma determinada lista explícita de procedimentos (e não outros) é financiada com dinheiro público, nascia a partir da necessidade de ampliar o acesso aos serviços para a população indigente dentro programa federal de assistência MEDICAID. A introdução no Reino Unido e Nova Zelândia de um mercado interno ao sistema de saúde incidiu, de modo determinante, sobre a escolha desses países por um mecanismo de racionamento que podemos assimilar ao supracitado, chamado para a seleção, aquele que indicaremos como racionamento para diretrizes. Não está claro sobre qual base ética se fundamentará o processo de escolha de prioridades. Isto pode não ser importante 
para a abordagem pluralista, uma vez que é baseado sobre bases éticas híbridas de seus participantes. O que é requerido é o reconhecimento da complexidade ética, combinada com a mudança do estilo e da natureza do debate. A força e a importância do "fazer ética" está em se fazer sensível à diversidade moral, ao pluralismo de nossa sociedade, à necessidade de respeito pelos outros e por seus valores, e, na maior parte dos casos, à necessidade de tolerância ativa. Em muitas das discussões sobre a escolha das prioridades falta a consciência da estrutura ética em que está referenciada. Cada grupo é provável que ocupe os seus próprios nichos éticos inconsciente do panorama circundante. As diferenças entre as diversas perspectivas sobre o todo, tendem a ser exageradas, especialmente quando a retórica suplanta a razão e o debate público. Reconhecendo o valor da abordagem multidisciplinar na escolha das prioridades se contribui para atenuar o que ainda continua a prevalecer: o conflito.

\section{Referências}

${ }^{1}$ Martino A, Bodini C. La salute negata: da Alma Ata ai Millenium Development Goals, e ritorno. In: Pellecchia U, Zanotelli F. La cura e il potere. Salute globale, saperi antropologici, azioni di cooperazione sanitaria transnazionale, v3., Editpress; 2010: 45-67.

${ }^{2}$ IMF World Economic Outlook Reports [Internet] Disponível em: http://www.imf.org/external/ ns/cs.aspx?id=29

${ }^{3}$ Hobsbawm EJ. Il secolo breve. 1914-1991: I'era dei grandi cataclismi. Milano, Rizzoli; 1995.

${ }^{4}$ Wacquant L. Punire i poveri: il nuovo governo dell'insicurezza sociale. DeriveApprodi; 2006.

${ }^{5}$ Karanikolos M et al. Financial crisis, austerity, and health in Europe. The Lancet 2013 381(9874): 1323-1331.

${ }^{6}$ Kentikelenis A et al. Health effects of financial crisis: omens of a Greek tragedy. The Lancet 2011 378(9801): 1457-1458.

${ }^{7}$ Stuckler $D$, et al. The public health effect of economic crises and alternative policy responses in Europe: an empirical analysis. The Lancet 2009 374(9686): 315-323.

${ }^{8}$ Schrecker T. Denaturalizing scarcity: a strategy of enquiry for public-health ethics. Bulletin of the World Health Organization 2008 86(8):600-605.

${ }^{9}$ Stefanini a Criteri e soggetti delle scelte nell'allocazione delle risorse in sanita. Teoria pratica ed esperineze straniere. In: Geddes M, Berlinquer G. La salute in Italia. Ediesse; 1998: 179-205

${ }^{10}$ Decreto Legislativo L. 502/92 e Decreto Legislativo 571/93 [internet] Disponível em: http:// www.normattiva.it/

${ }^{11}$ Franco TB, Wanderlei SB, Merhy E E. O acolhimento e os processos de trabalho em saúde: o caso de Betim, Minas Gerais, Brasil. Cad. saúde pública 1999 15(2): 345-353.

12 Hunter, DJ. Rationing dilemmas in health care. Birmingham: National Association of Health Authorities and Trusts; 1993.

${ }^{13}$ Schaefer M. Evaluation/decision-making in health planning and administration. Department of Health Administration, School of Public Health and Program in Health Services Evaluation, University of North Carolina at Chapel Hill; 1973. 


\section{Artigo Original}

${ }^{14}$ World Bank. World Development Report 1993, Investing in Health. Oxford: Oxford University Press; 1993.

${ }^{15}$ Gillon R. Philosophical Medical Ethics. Chichester: John Whiley; 1985.

${ }^{16}$ Beauchamp TL, Childress JF. Principles of biomedical ethics. Oxford: Oxford University Press; 1994. Ch. 6: Justice: 326-394.

${ }_{17}$ Whitehead M. The concepts and principles of equity and health. Health Promotion Int. 1991; 6(3): 217-227.

${ }^{18}$ Beauchamp TL, Faden RR. The Right to Health and the Right to Health Care. The Journal of Med and Philosophy 1979 4:118-131.

${ }^{19}$ Gudex C. QALYs and their use by the health service. Discussion Paper no. 20. York: University of York, Centre for Health Economics; 1986.

${ }^{20}$ Murray CJL. Quantifying the burden of disease: the technical basis for disability-adjusted life years. Bulletin of the World Health Organization 1994 72(3): 429-445.

${ }^{21}$ Gracia D. Fondamenti di bio-etica. Sviluppo storico e metodo. Milano: Edizioni S.Paolo; 1993.

${ }^{22}$ The Hastings Center, Appendix D: Values, Ethics and CBA in Health Care. In: Office of Technology Assessment, The Implications of Cost-Effectiveness Analysis of Medical Technology, Washington U.S. Government Printing Office, 1980: 168-182.

${ }^{23}$ Galbraith JK. The culture of contentment. London: Penguin; 1992.

${ }^{24}$ Rawls J. A Theory of Justice. Cambridge (MA), Harvard University Press; 1971.

${ }^{25}$ Oregon Health Services Commission. Prioritization of health services: a report to the governor and legislator. Salem, Oregon: State of Oregon; 1991.

${ }^{26}$ Dunning AJ. Choices in health care: a report by the government committee on choices in health care. Rijswicjk, Netherlands: Ministry of Health, Welfare and Cultural Affairs; 1992.

${ }^{27}$ Swedish Parliamentary Priorities Commission. Priorities in health care: Ethics, economy, implementation. Stockholm, Regeringskansliets; 1995.

${ }^{28}$ Cummings J. Core services and priority setting: the New Zealand experience. Health Policy 1994 29: 41-60.

${ }^{29}$ Engelhardt HT Jr. Foundations of bio-ethics. Oxford, Oxford University Press; 1986.

${ }^{30}$ Gracia D (1990), What constitutes a just health services system and how should scarse resources be allocated? Bulletin of the Pan American Health Organization 24(4): 550-565.

${ }^{31}$ Bentham J (1776). A Fragment on Government. London., Preface (2nd para.) [Internet] Disponível em: http://www.efm.bris.ac.uk/het/bentham/government.htm

${ }^{32}$ Carr-Hill R. Allocating resources to health care: is the QALY a technical solution to a political proble? Int Journal of Health Services 1991 21(2): 351-363. 